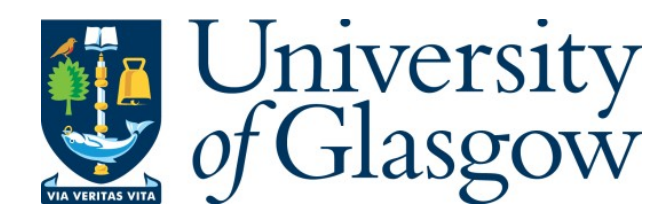

Happer, C., and Philo, G. (2016) New approaches to understanding the role of the news media in the formation of public attitudes and behaviours on climate change. European Journal of Communication, 31(2), pp. 136-151.

There may be differences between this version and the published version. You are advised to consult the publisher's version if you wish to cite from it.

http://eprints.gla.ac.uk/113171/

Deposited on: 09 August 2016

Enlighten - Research publications by members of the University of Glasgow http://eprints.gla.ac.uk 


\title{
New approaches to understanding the role of the news media in the formation of public attitudes and behaviours on climate change
}

\section{By Catherine Happer and Greg Philo}

\begin{abstract}
This article examines the role of news media on climate change and sustainable energy in the shaping of audience opinions and beliefs and the possible relation of these to behaviours. It reports on a series of studies conducted between 2011-2014 which develop existing approaches to audience reception analyses by using innovative methodologies which focus specifically on the negotiation of new information in response to existing beliefs, perceptions and behavioural patterns - both in the short and long term. Audience groups are introduced to new information to which the range of responses are examined. This approach allows for an exploration of the interplay of socio-political and personal factors as well as the identification of the potential informational triggers for change. The findings suggest that media accounts are likely to have a shaping role in relation to behaviours under a range of specific and coinciding conditions.
\end{abstract}

Keywords: climate change, media, news, audiences, public attitudes

\section{Introduction}

The connection between public consumption of mass media and subsequent behaviours has been the subject of much debate. The view of the contemporary world as composed of passive and isolated individuals who are subject to the 'effects' of powerful propaganda messages has long been considered obsolete in communications research. While early debates about the power of audiences to resist media messages focused on the polysemy of the text (Morley, 1980; Hall, 1981), in the digital environment, conceptions of the 'audience' are 
being redrawn to reflect the greater potential for participation in public life (Jenkins 2006; Mossberger et al. 2008) and the more 'interactive' relationship individuals have with the range of media at their disposal (Bruns, 2009; Poster, 2009) However, as Curran and others note in Britain, in spite of the potential offered by digital media, there is currently no demand for significant political or cultural change (Curran et al. 2012), and strong evidence for the continuing role of the mass media in shaping public understanding (Davis, 2006; Philo and Berry, 2011; Briant et al., 2011).

Research conducted by the Glasgow University Media Group has shown the conditions under which media messages do sometimes produce significant changes in behaviour; for example, in relation to fears about HIV/AIDS (Kitzinger, 1990; Miller, 1998). Research in the area of health indicates that the media can have significant impacts (Boyce, 2007; Hilton et al., 2012); public campaigns and the promotion of information making the link between smoking and cancer, for example, have clearly produced behavioural change (Collins, 2013). But there are also examples in which new information does not produce such changes and the literature illustrates that the wide range of information in the media about climate change often fails to do so. Our new work focuses on the conditions under which changes in beliefs and attitudes occur and the factors which may inhibit this.

\section{Attitudes to climate change}

There is a substantial body of work looking at public attitudes towards climate change: it is cross-disciplinary, inconsistent and subject to varying methodologies (Pidgeon, 2010; Upham et al., 2009). One of the key trends, most significantly in the English-speaking world, is the existence of what Moser and Dilling (2007a) refer to as a 'persistent conundrum'; that in spite of high levels of awareness and concern about climate change (Lorenzoni et al. 2007; Eurobarometer, 2007; 2009; Pidgeon, 2010), it is not considered an issue of high priority 
(Moser and Dilling, 2007a; ICM/Guardian, 2012). Another key finding across the research is that attitudinal positions towards the issue do not appear to be fixed and levels of scepticism, although low and often inconsistent, seem to alter frequently (Upham et al., 2009).

Some commentators (Nisbet and Myers, 2007; Pidgeon, 2010) have attempted to associate changes in public concern and growth in scepticism regarding climate change to media attention, and other researchers have examined the complex and dynamic process by which media messages influence belief (Moser and Dilling, 2007b; Kahan et al., 2007; Whitmarsh, 2011; Moser and Dilling, 2010). Research by Lieserwitz et al. (2009; 2012) indicates that membership of cultural groupings, values and political ideologies are significant factors in shaping public interpretations of climate change, and also drive the information which people seek. In their work, Kahan et al (2007; 2011) similarly apply a cultural cognition model to argue that people routinely seek evidence that supports their existing views, and discount counter evidence suggesting significant potential to resist media messages. In the digital environment in which audiences increasingly tailor their media consumption, these arguments have particular resonance. However, broader questions of the way in which the media focus interest on particular issues, and potentially play a role in developing the connections between political leanings and particular perspectives must also be addressed (Happer and Philo, 2013). For example, in relation to climate change, it is important to consider the range of conflicting perspectives offered by digital media with which the public might choose to align themselves.

The body of work which focuses on patterns of mainstream media coverage on climate change identify two strong tendencies which are likely to impact on attitudinal patterns. The first is the way in which the journalistic aim of 'balance' has led to the construction of climate change as a subject of uncertainty, with a tendency towards the disproportionate inclusion of sceptical voices in debates (Boykoff and Boykoff, 2004, 2007; BBC Trust, 2011; 
Painter, 2013). Research focusing on digital media has shown that sceptical content online, though less prominent, is often aligned to mainstream media reporting (Lockwood, 2008; Gavin and Marshall, 2011). The second trend is a tendency for the issue to be subject to peaks and troughs in media attention (Fischer, 2011; 2013). Since 2010 global media coverage of climate change has dipped dramatically - Dailyclimate.org noted that '2010 was the year that climate change fell off the map’ - and this mirrors a fall from the UK political agenda in recent years (Philo and Happer, 2013).

\section{The gap between attitudes and behaviours}

The relationship between attitudes and engagement at the level of behaviours in relation to climate change has been the subject of much investigation. Researchers such as Lorenzoni et al. (2007) and Moser and Dilling (2010) base their arguments about media influence on a conception of climate change engagement which incorporates a cognitive, emotional and behavioural dimension:

i.e. people grapple mentally with and gain understanding of the issue; experience an emotional response, such as interest, concern, or worry; and actively respond by way of changes in climate-relevant behavior or political action. (Moser and Dilling, 2010: 162)

This conceptualisation of engagement clearly involves an association between attitudes - how people feel about issues in response to information about them - and their subsequent behaviour. Where attitudes are not associated with behaviours this is sometimes called the ‘value-action gap’ (Blake, 1999). Researchers have explored the various barriers which exist to prohibit engagement with positive environmental behaviours in spite of sympathetic attitudinal positions (Bedford et al., 2010; Whitmarsh et al., 2011). A range of studies suggest that the perceived remoteness of climate change as an issue, in relation to geography 
or temporality, prevent the public from connecting with it at a personal level (Lorenzoni and Pidgeon, 2006; Whitmarsh, 2008; Leiserowitz et al., 2009). In addition, inadequate systems of provision and structural barriers also interact with the processing of information to construct positions which do or do not lead to behavioural change (Whitmarsh et al., 2011). Our new research develops methodologies using focus groups that make it possible to identify the specific informational triggers for changes in patterns of understanding and attitude and the key factors in the altering of people's behavioural commitments.

\section{Methodology}

The methodology has been developed over a series of studies conducted between 2011-2014 which examined the way in which attitudinal and behavioural commitments are negotiated in response to media accounts of a range of climate change and broader issues around sustainable energy. For this work, the qualitative technique of focus groups was chosen as the dominant method as it is the most effective in illuminating the process by which attitudes and beliefs develop in response to a range of factors including new arguments and information. The approach involves three stages. The first stage is to examine the nature and sources of belief and opinions on climate change and sustainable energy, including discussions of the way in which concerns about these issues may result in specific behaviours and inhibiting factors in relation to these.

The second stage involves introducing new information. Our aim is to immerse respondents in an information environment in order to recreate as much as possible the conditions under which new information would be received. For the first study we developed future scenarios showing the potential effects of climate change both at the global and the local level. One, for example, focused on a mass flood in Bangladesh which forced the migration of millions of the population with direct implications for the UK. These scenarios were developed through 
detailed research and consultation with scientists and experts and produced as news reports across a range of media. The reports varied in respect of their perspective on the scientific arguments and impacts of the stories to reflect the differing ideological preferences and approaches of the range of news outlets. The scenarios were presented as predictions of possible futures. In the 2014 study existing footage was shown including a video of climate change representative, Yeb Sano, pleading with the world to take action to reduce CO2 emissions in an emotional speech about the devastating effects of Typhoon Haiyan. It was presented to participants as one of the range of perspectives that might be included in coverage of climate change - in this case in response to an event with which most were familiar. In both studies the primary aim of the new information was to identify potential triggers for attitude and behavioural change.

After introducing the new information, group discussions are conducted which focus on the elements which affect the individual members, opinions about appropriate responses under a range of different conditions, the level of individual and collective responsibility and the likelihood of such information impacting on behaviour. The aim is to identify the pivotal points at which opinions and attitudes might be altered. In the earlier study, a longitudinal element was incorporated in which we interviewed half of the original sample six months after the research to assess the impact of the new information upon audiences beliefs, understandings and the potential altering of opinions and behavioural commitments. This allowed us to compare not only the way in which media messages were ingested in the shortterm, but also how they impacted over time.

\section{Sample}

We are reporting on a total sample of 150 respondents across the studies, the first of which was conducted in 2011 with a follow-up in 2012 and a further study in 2014. This involves 
26 distinct groups. In the earlier study we held 12 groups in the first wave and interviews with 28 from the original groups in addition to six new groups in the second wave six months later. These functioned as a control and mirrored in demographics and location the original six groups from which we recruited our phone interviewees. In the latest study, we held 8 groups. Focus groups were made up of six people on average and were recruited on the basis of their being from the same socio-economic group and being naturally occurring. By this we mean groups who would normally congregate and speak to one another in the regular course of their lives and therefore have a pre-existing rapport which can be tapped into in the groups. Thus the groups were drawn from people who work together, such as cleaners and janitors, students who house-share or those who interact via their local communities. The groups were recruited to represent the normal socio-demographic criteria and were also geographically diverse. We included groups of specific interest. In the first study, for example, we included two groups from the Norwich area which was selected due to its being an area under threat specifically from coastal erosion. The inclusion of these groups allowed us to assess whether the immediacy of such a threat made any difference to attitudes and behaviour. Groups from Oxford University were also included with participants who had direct links to politicians and political bodies which gave us a chance to assess the impact of this on feelings of empowerment or agency. We also had a particular interest in the views of young people since there is continual debate on their consumption of media via digital technologies which is an increasingly important aspect of contemporary communications. Hence in the second study, young people were particularly well represented in the sample which was drawn from the extended Glasgow City area.

\section{Stage One: existing beliefs, attitudes and assessments of information}

In the first stage of each study we examined the range of beliefs, opinions and commitments to behaviours in relation to climate change and sustainable energy. In the 2011-12 study, we 
sought to gain access to respondents' immediate thoughts on and associations with climate change. Respondents offered a range of responses which were often a long list of ideas and images and, in some cases, emotional responses which, respondents themselves acknowledged, were very diverse. These included a mix of key terms - such as 'global warming', ‘ice melting', and 'greenhouse gases'- as well as lists of related terms such as 'pollution, ozone, green energy' and 'population growth'. One respondent simply said ‘controversial media topic'. Most admitted they didn’t have a clear understanding of the causes and potential threats. This lack of clarity on the issue of climate change has been consistent across the studies.

That there is a range of information yet a lack of clarity on climate change and other energyrelated issues, derives from the manner in which the issues are contextualised in an intense media environment. Young people, in particular, noted that, in the digital arena where information exists to represent any argument and challenge any evidence, trust and credibility were increasingly difficult to assess. On climate change, respondents said they had received information from a range of sources across media and the majority were aware of conflicting arguments about the science. In terms of trust, scientists and academics rated most highly, cited by more than one fifth of the 2011-2012 samples. This was attributed to their providing information perceived to be 'straight from the horse's mouth'. However, the general trust in scientists was undermined by a sense that the science itself was lacking in concrete evidence, and, as a result, the scientists often argued amongst themselves. There was a perception that the alleged 'wooliness' had been used by politicians, corporate and other interest groups to serve their own agendas. These comments from students illustrate how this leads to lack of trust: 
Female speaker: And we know that climate change is basically used by politicians, scientists and business, people who run you know oil companies or whatever, it's used as a -

First male speaker: Form of rhetoric.

Second male speaker: Yeah, it's used to like, you know, gain some margin on someone else, or it's used because they have a vested interest in what they're talking about, so it's very hard to know who to trust when talking about climate change. (Student, Oxford, 2011-12)

Politicians were the least trusted group, cited by more than a quarter of respondents from the 2011-12 samples, and discussions showed that a majority believed they could not relied upon to act in the best interests of the public. In discussions of credibility, perhaps the most significant finding was therefore the lack of public trust that currently exists both in relation to climate change and the range of groups speaking about it - and the consequential tendency to question the credibility of all related information.

\section{Inhibitors to behavioural change}

In spite of this lack of clarity, findings across both studies showed evidence of existing general sympathies towards climate change, but they also showed that these were not always translated into behavioural change which was consistent with previous studies. The large majority of both samples said that they believed that action should be taken on climate change when specifically asked, and very few fundamentally rejected the science. However, in spite of the initial responses, discussions demonstrated that only a small minority had made changes that were directly related to their personal beliefs on climate change. We therefore sought to identify the inhibitors to behavioural change that were in place. 
Our findings supported the view that structural barriers are an important factor. For many people decisions about activities such as driving less and consuming less energy were led by considerations of cost and convenience as this comment shows:

Female speaker: I certainly take conscious decisions in my life to think well I could walk to the shops but I still drive my kid to school every day so...when it’s convenient to me, I will do it. If it’s not convenient I really do have to think about it. (Middle class group, Norfolk, 2011-12)

Similarly to Kahan et al. and Lieserwitz et al., we found that existing belief systems were a central factor in the interpretation of media messages. The widespread lack of trust in public figures, and specifically those who would be expected to take action on climate change, was even more significant than political ideologies in this respect and was a crucial factor in dismissing arguments about the need to act as this comment illustrates:

Female speaker: It seems that by the time we hear about it, the politics are already in place, things are already being done, this is just whitewashing it for the newspapers, it's already been done and nothing you do can do about it... (Part-time and shop workers, 2014)

The widespread lack of trust in decision-makers to act in the public good, and the consequential feeling of having no public voice, had a direct impact on perceptions of individual and/or collective agency which evidence suggested was a key factor in the process by which people assess the need to make behavioural changes. Significantly a group of Oxford students from the 2011-12 sample, who placed higher levels of trust in public figures some of which was based on personal experience of them, did not report feeling the same levels of powerlessness. In fact, they felt that their actions could be socially important. The only other group which did not report the wider feelings of powerlessness was one of the Norfolk resident groups also from the earlier 
sample. The members of this group were very active in the community, and a majority had attended public meetings and events, some of which was related to their belief for the need for action on coastal erosion. As a result they felt they had some power to change things, as this exchange shows:

Facilitator: Do you believe you can change and alter things a bit?

Female speaker: It depends on the persistence and strength of your pressure group if you are but that is the only way you are going to do it.

Male speaker: I'm a continual optimist and I believe that as an individual I do have some effect but time and time again, I'm proved wrong but I'm still an optimist

Facilitator: But you would go on websites and you've already raised that. Do other people feel the same as this?

All: Oh, yes.

Female speaker: I'd be prepared to stand up and be counted. (Middle class group, Norfolk, 2011-12)

However the majority felt that individual behaviours did not make a difference on an issue such as climate change. Part of this was the question of governments, nationally and internationally, not always acting in the public interest, but part of it was a sense of the enormity of the challenge of climate change. In both groups, it was expressed that the perceived failure of global and national politicians to act on climate change impacted on their own commitment to do so, as this exchange shows: 
Female speaker: It just makes me feel like even more, like, I wish, on a bigger level that the UN and world governments would get organised and then I'd happily chip in for whatever they needed me to do... but if I go home...

Facilitator: So energy efficiency [in the home] isn’t going to make any difference?

Female speaker: I think because as individuals you can feel so powerless at times, there is that kind of need to be led by a greater power into it...(Middle class professionals, 2014)

Individual changes were perceived by some to be simply a 'drop in the ocean'. The politicians' failure to act gave some legitimacy to this belief - and indeed to their own lack of action.

There was also evidence that the media played a role in inhibiting behavioural commitments with the decline in coverage of climate change in recent years being a factor (Fischer 2011; Fischer 2013). The tendency for media to set agendas and focus public interest on particular subjects, and to limit attention on climate change in this case, was evident across all waves of research. There was an awareness that climate change was less in the media than it had been in the past and therefore it was talked about and considered less. In the later study the way in which this operated with digital and social media was more clearly shown. Particularly for those groups who reported frequent digital media usage, usually accessed through portable devices, there was a recognition that social media tended to focus the attention of users intensively on the same subjects. As one respondent observed part of the appeal of social media was to be 'in with the masses' and to be talking about a selected range of topics at any given time. As much of the stimulus for social media is the mainstream media (Newman, 2011), the fact that climate change is receiving limited attention in the latter limits its visibility in the former. In this way then the media coverage had helped to shape perceptions 
that the issue wasn't a top priority, and combined with feelings about personal powerlessness had played a pivotal role in inhibiting potential behavioural change.

\section{Stage two: the new information}

We introduced new information to our audience members in order to identify more specifically the possible informational triggers for attitudinal and behavioural change. We had first established, in detail, respondents’ positions on climate change and other energy issues and the informational, structural and broader attitudinal foundations of these.

Alterations in former positions were therefore clearly indicated by the range of responses to the new information. Our study provided support for the argument the 'remoteness' of the issue is a significant inhibitor to prioritising it (Lorenzoni et al. 2007; Moser and Dilling, 2007a, Lieserwitz et al., 2009) in that the more directly impacting the information, the greater likelihood it had of shifting attitudes and potentially behaviours. For example, in the earlier study, the Bangladesh refugee story affected respondents most. The greater level of concern and urgency generated was related to the way this scenario connected with common fears about increased levels of immigration and the associated problems. The more closely increased immigration was thought to affect respondents directly, the more climate change was seen to be a priority. Ethnicity was a key factor in this respect. Those from ethnic minority groups were worried about the impact of great numbers of refugees in their own communities and the consequences for their own security. This comment from an Asian man living in Glasgow explains his specific concerns:

Male speaker: If I’m honest, I'm thinking how it will affect me as a minority because they're the same as me - know what I'm trying to say?... there's only a certain number, amount of resources, and how it's going to affect the community already here. (Middle class, Govanhill residents, 2011-12) 
The sense that direct impact or relevance was key was supported by responses to the video focusing on the effects of Typhoon Haiyan shown to the respondents in the 2014 study. The large majority had a very strong response to the devastation described by the UN representative, which increased their concerns about climate change. This was grounded in existing fears about changing and/or extreme weather which, across these and other studies (Lieserwitz et al. 2009), was considered to be the most convincing evidence of climate change. As one respondent noted:

Female speaker: When you hear something like this, tsunami, that's when your brain does think 'climate change, we need to do something', that's the only time. (Part-time and shop workers, 2014)

It was also the way in which most people felt they would, if that had not already, directly experience the effects of climate change, which increased the sense of urgency and concern. As this respondent expressed, weather is not something that can be easily ignored:

Female speaker: If you're walking about in October and it’s snowing, you can’t not think about it - I think about climate change - and it’s worrying me so much. (Office workers, 2014)

These findings emphasise the importance of communicating risks which can directly relate to people's experience. To gauge the level of impact on attitudes of the new information, we asked respondents from the 2011-12 to assess how important climate change was to them on a scale of 1 to 10 both before and after the new information was introduced. The majority of respondents increased the rating across the sessions - with nearly double the number giving it the top rating. This considerable increase indicates the potential for information to impact on attitudes in the short-term. However, when we asked our respondents across both studies about the impact of the new information upon their behavioural intentions, we found a 
marked lack of commitment to behavioural change. This comment in response to the Typhoon Haiyan video is illustrative:

Male speaker: What I'm trying to say is that, you say we need more hard-hitting? How many hard hitting news is there about crime and we have changed? How many times every week we see typhoons and earthquakes? It hasn’t made any difference. (Small business owners, 2014)

As Lorenzoni et al. (2007) note, engagement exists at the level at which knowledge and real concern are accompanied by the will and ability to act. In our studies, the majority of respondents gained the first two, but the original reasons for not taking action were widely repeated: that individuals alone are powerless, changes have to be made at the level of government (who are not trusted) and that it was not clear what more could be done once issues of cost and convenience were considered.

\section{Stage three: the revisits}

The longitudinal findings from the 2011-12 study confirmed that the majority had not made changes to their behaviour. However perhaps our most interesting finding was that in spite of these barriers and belief systems, in our longer term research we did actually find a sizable minority who changed their behaviour in response to the information that they received. These tended to be people who found their opinions strengthened by the experience of taking part in the focus groups rather than radically altered, suggesting that a key factor is an existing openness to behave more 'ethically'. It was also significant that those who had made the greatest changes included respondents for whom the information had had a considerable personal impact. An Asian bakery owner, for example, believed that the Bangladesh scenario threatened her security and that of her own community and the concern it generated had become deep-rooted in the preceding six months. She explains what she had 
done in response to the group discussions and new information:

Female speaker: Well, before this group I was very much aware - what with my business (bakery) - of recycling, but I've now found a company that will recycle my waste ...

Facilitator: Would you say that was a direct result of the group?

Female speaker: When I opened my bakery I looked around but I didn’t find anything...I wanted to do it anyway, but after the group I just tried a bit harder. (Middle class, Govanhill, 2011-12)

Amongst the majority however we found evidence of a continuing ‘value-action gap’ (Blake, 1999), in that in spite of beliefs in the need for action on climate change, and the increased concern generated by the materials in the short term, the majority of interviewees had not changed their behaviour since the first wave of research. The reasons for disengagement were long established in the majority of people and, examining the attitudinal changes that had taken place over the six months, it was clear that perceptions of individual power or lack of were key. Across the period there had developed in the majority a clearer and more urgent sense that decisive action was important and would have to be taken. There was a strong feeling that governments would need to lead the changes, including behavioural change. There was an acceptance, for example, that air travel might have to be curbed or made more expensive. Our research indicated that if a clear lead was given, and clear explanations for the need for the changes to be made then the public would, however grudgingly, accept it, as this comment illustrates:

Male speaker: If I can understand the rationale for it, and felt like this was part of a longer term plan, not a kind of short-term initiative that wasn't kind of linked in to a 
broader plan to try and change the way in which we manage our resources. (Middle class professionals, 2014)

We also found that media accounts played a role in triggering both attitudinal and behavioural change. In terms of the development of positive changes, the media construction of climate change as a subject of uncertainty was strongly implicated in the conflicts in understanding and trust. The sense of not knowing who or what to trust in terms of the most effective course of action, rooted in the proliferation of media opinions and arguments, continued to be cited as a significant barrier to action. It was further compounded by the lack of attention to climate change across media which led people to de-prioritise it in their own minds. The follow-up interviews showed the way in which the impact of communications which rooted risks in the scientific model was undermined by the respondents return to a wider media culture which consistently reinforces the message of uncertainty. This is supported by our finding of a connection between the level of exposure to media coverage and strength of attitude on the subject and the degree to which it is likely to be altered by new information. We found that those who had been least exposed to coverage were most open to adjusting their views and conversely those who arrived at the groups with most exposure were least likely to have their opinions and attitudes altered. As a result the degree of exposure to sceptical coverage, of which there is a great deal, is likely to be implicated in how open people are to develop the attitudinal sympathies that are most likely to be translated into behavioural change.

\section{Conclusions and future research}

Climate change is a collective action problem, and will not be solved without the consent of the public either to facilitate policy change and/or to potentially make the collective behavioural changes required. The role that the media might play in promoting or prohibiting 
these changes is therefore of paramount importance. The innovations of our methodological approach lie in the three-phased look at audience reception which makes it possible to isolate the specific informational triggers for change across a range of materials. This provides a new and in-depth insight into the way in which media accounts interact with existing beliefs, structural barriers and values to drive change in attitudes and behaviours - or to inhibit these as well as to indicate the kinds of materials that might be powerful, to whom and in what context. There are three key aspects to our findings.

The first point relates to the quality of information that is available. The range of conflicting messages about climate change across the media have contributed to current confusions and uncertainties, as well as to the broad levels of disengagement with the issue. Media accounts have largely failed to connect with the public at a personal level. Our research suggests that communicative approaches which emphasise risks which people can directly relate to and which are rooted in a solid science are effective. The language of risk is increasingly being used in climate change communications and our findings would support the validity of that approach (Painter, 2013). However, the importance of messages reflective of the scientific consensus across media cannot be under-estimated. Whilst, as in any scientific field there will be disagreement on the more specific areas, the basic arguments about anthropogenic climate change should be the foundation of any discussion - as is the case with, say, the links between smoking and cancer. The media's role is to make the public aware of the plurality of perspectives and provide a fair critique but not at the expense of misinforming audiences. A key factor in this respect is that the public is not hearing trusted speakers such as the climate scientists and therefore the majority do not know that there is a high level of consensus across the scientific community. Evidence suggests this knowledge would limit the potential to dismiss the arguments being made about the need for action.

Beliefs and perceptions about individual and collective agency are also centrally important in 
the degree to which people are motivated to act. We found specifically that disengagement was rooted in a general distrust of political figures and the attendant perception of individual powerlessness for many. The broader culture of cynicism and distrust, fed by coverage of a range of public scandals, can also be associated with an extended cross-media culture in which all information can potentially be countered with conflicting information. This makes it very difficult for audiences to make accurate decisions about credibility and accuracy. These challenges extend beyond information about climate change, and are faced by mobile multi-media users across all issues often at great speed. Perceptions of individual powerlessness are fuelled by the (reported) actions of politicians, and the sense of them being unaccountable, but also the mainstream media's conventional tendency to develop narratives about the actions of governments and inspiring figures in driving change, rather than the more nuanced picture of the role of the collective, and of the individuals within it.

The central question however of this research has been; what ultimately drives people to make behavioural changes? Our findings suggest that the kind of effective media accounts discussed may provide the final motivational factor for individuals who possess sympathetic attitudes, often with unmet behavioural commitments, as well as a belief that action is meaningful and who do not face barriers to carrying these out. Structural support - for example, in the form of removing barriers such as cost - are pivotal to the realisation of behavioural commitments. However, the nature of information and the way it is delivered are important. Whilst the media do not tell us how to think or behave, they are crucial in focusing attention and constructing behavioural possibilities, whilst also limiting arguments or evidence that might counter these. Audiences have a range of resources such as past experience and knowledge to draw on and resist media messages, but in the case of climate change in relation to which most people know very little, the construction of scientific uncertainty has proved very powerful. However the substantial response to directly 
impacting materials on climate change highlights the way in which attitudinal and behavioural positions may alter - and we have presented a dynamic model which also highlights the potential for public resistance as well as the possibilities for social change.

\section{Funding}

The authors received financial support from the UKERC, and Glasgow City Council.

\section{Competing Interests}

The authors have declared that no competing interests exist.

\section{Acknowledgments}

We would like to thank Antony Froggatt, Estelle Rouhaud, Daniela Latina, Giuliana Tiripelli and the members of the Glasgow University Media Group.

\section{References}

Bedford, T., Collingwood, P., Darnton, A., Evans, D., Gatersleben, B., Abrahamse, W and Jackson, T. (2010) 'Motivations for Pro-environmental Behaviour: A report to the Department for Environment’, Food and Rural Affairs. London, Defra: RESOLVE. BBC Trust (2011) ‘BBC Trust review of impartiality and accuracy of the BBC’s coverage of science'. Available at:

http://downloads.bbc.co.uk/bbctrust/assets/files/pdf/our_work/science_impartiality/science_i mpartiality.pdf

Blake, J. (1999) 'Overcoming the 'value-action gap' in environmental policy: Tensions between national policy and local experience'. Local Environment 4(3): 257-278.

Boyce, T. (2007) Health, risk and news: The MMR vaccine and the media. London: Peter Lang. 
Boykoff, M.T. and Boykoff, J.M. (2004) 'Balance as bias: global warming and the US prestige press’. Global Environmental Change 14: 125-136.

Boykoff, M. T. and Boykoff, J. M. (2007) 'Climate change and journalistic norms: A casestudy of US mass-media coverage’. Geoforum 38(6): 1190-1204.

Briant, E., Philo, G., and Watson, N. (2011) 'Bad News for Disabled People: How the Newspapers are Reporting Disability’. Report for Inclusion London.

Bruns, A. (2009) Blogs, Wikipedia, Second life, and Beyond: from production to produsage. New York: Peter Lang

Collins, N. (2013) ‘Smoking, drinking and drug use fall dramatically among children’. The Telegraph, $26^{\text {th }}$ July. Available at:

http://www.telegraph.co.uk/health/10202902/Smoking-drinking-and-drug-use-falldramatically-among-children.html

Curran, J. and Witschge, T. (2010) 'Liberal dreams and the Internet'. In N. Fenton, (ed) New Media, Old News: Journalism \& Democracy in the Digital Age, pp. 102-118. Los Angeles, CA: Sage.

Curran, J., Fenton, N. and Freedman, D. (2012) Misunderstanding the Internet. Oxon: Routledge.

Davis, A. (2006) 'Media Effects and the question of the rational audience: lessons from the financial markets’. Media Culture Society 18(4): 603-625.

Eurobarometer (2007) 'Attitudes on issues related to EU Energy Policy - Analytic report' (Flash Eurobarometer 206a). Europe: European Commission. 
Fischer, D. (2011) '2010 in review: The year climate coverage “fell off the map”'. The Daily Climate, $3^{\text {rd }}$ January. Available at: http://wwwp.dailyclimate.org/tdcnewsroom/2011/01/climate-coverage

Fischer, D. (2013) 'Climate coverage, dominated by weird weather, falls further in 2012'. The Daily Climate, $2^{\text {nd }}$ January. Available at: http://wwwp.dailyclimate.org/tdcnewsroom/2013/01/2012-climate-change-reporting

Gavin, N.T and Marshall, T. (2011) 'Mediated climate change in Britain: Scepticism on the web and on television around Copenhagen', Global Environmental Change 21(3): 1035-1044.

Hall, S. (1981). 'Encoding and Decoding in Television Discourse’. In Hobson, D., Hall, S., Lowe, A. and Willis, P. (ed), Culture, Media, Language, pp. 128-138. London: Hutchinson. Happer, C. and Philo, G. (2013) 'The Role of the Media in the Construction of Belief and Social Change’. Journal of Social and Political Psychology, 1(1): 321-336.

Hilton S., Patterson C. and Teyhan A. (2012) 'Escalating coverage of obesity in UK Newspapers: the evolution and framing of the "Obesity Epidemic” from 1996 to 2010'. Obesity 20:1688-1695.

ICM/Guardian (2012) 'Guardian/ICM poll on climate change, economics and politics', $26^{\text {th }}$ June. Available at:

http://www.theguardian.com/environment/interactive/2012/jun/26/guardian-icm-polleconomic-climate-change Jenkins, H. (2006) Convergence culture: where old and new media collide. New York: New York University Press. 
Kahan, D. M., Braman, D., Slovic, P., Gastil, J. and Cohen, G. L. (2007) ‘The Second National Risk and Culture Study: Making Sense of - and Making Progress In - The American Culture War of Fact’. GWU Legal Studies Research Paper: Yale Law School, No. 370. Kahan, D., Jenkins-Smith, H. and Braman, D. (2011) ‘Cultural Cognition of Scientific Consensus’. Journal of Risk Research 14: 147-74.

Kitzinger, J. (1990) ‘Audience understandings of AIDS media messages: a discussion of methods’. Sociology of Health \& Illness 12 (3): 319-35.

Leiserowitz, A. et al. (2009) 'Climate Change in the American Mind', Yale University and George Mason University. New Haven, CT: Yale Project on Climate Change Communication. Available at: http://gse.uml.edu/carbonsmarts/Leiserowitz.pdf

Leiserowitz, A., Maibach, E., Roser-Renouf, C., Smith, N., and Dawson, E. (2012) 'Climategate, public opinion, and the loss of trust'. Working Paper: American Behavioral Scientist. Available at:

http://environment.yale.edu/climatecommunication/files/Climategate_Opinion_and_Loss_of_ Trust_1.pdf

Lockwood, A. (2008) 'Seeding doubt: how sceptics use new media to delay action on climate change’. Conference Paper: Association for Journalism Education ‘New Media, New Democracy?' Sheffield, 12 September. Available at: http://cstpr.colorado.edu/students/envs_4800/lockwood_2008.pdf Lorenzoni, I. and Pidgeon, N.F. (2006) 'Public views on climate change: European and USA perspectives’, Climatic Change 77: 73-95. Available at: http://www.atmosp.physics.utoronto.ca/people/lev/ESSgc/lorenzoniPclimchng06.pdf 
Lorenzoni, I., Nicholson-Cole, S. and Whitmarsh, L. (2007). 'Barriers perceived to engaging with climate change among the UK public and their policy implications', Global Environmental Change 17(3-4): 445-459. Online at: http://www.sciencedirect.com/science/article/pii/S0959378007000209

Miller, D. (ed) (1998) 'Rethinking Northern Ireland: Colonialism, Power and Ideology'. London:Longman.

Morley, D. (1980) The 'Nationwide' Audience: Structure and Decoding. London: BFI. Moser, S.C. and Dilling, L. (2007a) 'Creating a climate for change: Communicating climate change and Facilitating Social Change’, pp.1-27 in Moser S. C. and Dilling, L. (eds) Creating a Climate for Change: Communicating Climate Change and Facilitating Social Change. UK: Cambridge University Press.

Moser, S.C. and Dilling, L. (2007b) 'Toward the social tipping point: creating a climate for change’, pp. 491-516 in Moser S. C. and Dilling, L. (eds) Creating a Climate for Change: Communicating Climate Change and Facilitating Social Change. UK: Cambridge University Press.

Moser, S. C. and Dilling, L. (2010) ‘Communicating Climate Change: Opportunities and Challenges for Closing the Science-Action Gap’. In Norgaard, R., Schlosberg, D. and Dryzek, J. (eds) The Oxford Handbook of Climate Change and Society, pp. 161-174. UK: Oxford University Press.

Mossberger, K., Tolbert, C. J. and McNeal, R. S. (2008) Digital citizenship: the internet, society, and participation. Massachusetts: MIT Press.

Newman, N. (2011) "Mainstream media and the distribution of news in the age of social discovery.” Reuters Institute for the study of Journalism. Available at: 
https://reutersinstitute.politics.ox.ac.uk/fileadmin/documents/Publications/Working_Papers/ Mainstream_media_and_the_distribution_of_news_.pdf

Nisbet, M.C. and Myers, T. (2007) ‘Twenty years of public opinion about global warming’. Public Opinion Quarterly 71(3): 444-470. Available at: http://climateshiftproject.org/wpcontent/uploads/2013/01/NisbetMyers2007_20yrsGWOpinion_POQ.pdf (accessed: 10th March 2014).

Painter, J. (2013) Climate Change in the Media. New York: Reuters Institute of Journalism. Philo, G. and Happer, C. (2013) Communicating Climate Change and Energy Security: New Methods in Audience Research. Routledge: New York.

Pidgeon, N.F. (2010) 'International Dimensions of Climate Change, Report 5: Public Understanding of and Attitudes Towards Climate Change’. Foresight: Government Office for Science. Available at: http://www.bis.gov.uk/assets/foresight/docs/internationaldimensions/11-1021-public-understanding-of-climate-change.pdf Poster, M. (2009) 'The Culture of Underdetermination'. In Lievrouw, L. and Livingstone, S, (eds) New Media, Vol I (Chapter 6). London: Sage

Upham, P., Whitmarsh, L., Poortinga, W., Purdam, K., Darnton, A., McLachlan, C. and Devine-Wright, P. (2009) 'Public Attitudes to Environmental Change: A Selective Review of Theory and Practice. A Research Synthesis for the Living with Environmental Change Programme’. Research Councils UK. Available at: http://www.lwec.org.uk/sites/default/files/001_Public\%20attitudes\%20to\%20environmental \%20change_final\%20report_301009_1.pdf

Whitmarsh, L. (2008) 'Are flood victims more concerned about climate change than other people? The role of direct experience in risk perception and behavioural response', Journal 
of Risk Research 11 (3): 351-374. Available at:

http://psych.cf.ac.uk/home2/whitmarsh/Whitmarsh\%20J\%20of\%20Risk\%20Research\%2020

08.pdf

Whitmarsh, L. (2011) 'Scepticism and uncertainty about climate change: dimensions, determinants and change over time’. Global Environmental Change, 21 (2): 690-700.

Available at: http://www.sciencedirect.com/science/article/pii/S0959378011000173

Whitmarsh, L., Seyfang, G. and O’Neill, S. (2011) 'Public engagement with carbon and climate change: to what extent is the public “carbon capable”'. Global Environmental Change 21(1): 56-65. Available at:

http://www.sciencedirect.com/science/article/pii/S0959378010000701

\section{$\underline{\text { Appendices }}$}

2014 sample

The sample was composed of 8 distinct groups and a total of 50 participants. The groups were composed of:

1. Small business owners

2. Part-time and shop workers

3. Office workers

4. Middle class professionals

5. $\quad$ Service sector workers

6. $\quad$ Cleaner and janitors

7. Students, Group 1 


\section{8. $\quad$ Students, Group 2}

\section{1- 2012 sample}

The research was conducted across two waves and included 18 distinct groups and a total of 100 participants. This consisted of 12 groups in the first wave and six in the second wave six months later mirroring the composition of half of the first wave. The groups were composed of:

1. Middle class, mix of Asian and white, Govanhill, Glasgow

2. Low income, cleaners, Glasgow

3. Students, Oxford

4. Students, Oxford

5. High income group, Crowborough, Sussex

6. Middle class professionals, Crowborough, Sussex

7. Low income, mix of Afro-Caribbean and Asian, Hackney, London

8. Low income group, Bradford

9. Middle class, residents, Norfolk

10. Middle class, residents, Norfolk

11. Students, Glasgow

12. English students, Glasgow 